Thorax (1946), 1, 39-47.

\title{
STAINLESS STEEL WIRE SUTURE TECHNIQUE IN THORACIC SURGERY*
}

\author{
BY
}

\section{RONALD BELSEY}

From the Kewstoke Thoracic Unit, E.M.S. South-West Region

Before embarking upon any new surgical procedure or technique three conditions need to be fulfilled. First, it must be shown to be necessary ; secondly, there must be sufficient experimental evidence to justify a trial of the new method; and thirdly, any advantage the new may appear to have over the old must be shown to possess statistical significance before its final adoption is justified, unless there are overwhelming practical advantages such as greater simplicity or economy. If these three rules are observed there will be far less of the fashionable " try everything once" approach that is responsible for so much confusion and wasted effort.

Condition "one" was met by dissatisfaction with the high morbidity rate attendant upon certain thoracic operations. The patient's attitude to, and recollection of, an operation are governed largely by the complications that occur in the post-operative period. Whereas mortality rates are of greater interest to the surgeon, who fosters the illusion that his value to society is judged largely by the number of patients he does, or does not, slaughter ; to the patient the question of how prolonged will be the period of post-operative misery is of far greater moment than any consideration of immortality.

Ninety per cent of post-operative morbidity in thoracic surgery is probably caused by two complications: the bronchial fistula and bacterial infection. These brief notes constitute a preliminary report upon the efforts of the surgical staff at Kewstoke to eliminate or control these two bogies.

Condition "two" has been adequately answered by the volume of experimental work done in recent years upon the degree and type of tissue reaction to various foreign suture materials. The observations recorded by various experimentalists are remarkably consistent, and those of Wu and Pai (1943) are typical. They observed very little inflammatory tissue reaction to stainless steel wire in experimental wounds, as contrasted with the terrific reaction to catgut and somewhat less severe reactions to thread and silk. In wire wounds, fibroblasts were shown to be present in five days as compared with 14 days in silk wounds, and the resulting fibrosis was minimal. In infected wounds there was no greater reaction round the wire than in the rest of the wound, no sinus formation, and no delay in healing ; thread, on the other hand, invariably led to sinus formation, and

* Being a summary of a paper presented at the meeting of the Society of Thoracic Surgeons at Liverpool, November 1945. 
healing was delayed until the thread had been removed. In short, infected tissues ignore stainless steel, resent catgut, and reject thread. Other workers have measured the greater tensile strength of wire wounds. There is no deterioration in the properties of wire with the most rigorous methods of sterilization sufficient to ruin catgut or thread. Wire can be tied in reef-knots, and these when tied squarely show no tendency to slip, no matter how short the ends are cut.

The only serious disadvantage of wire as a suture material lies in the technical difficulty of its manipulation. The wire is difficult to see against the background of the wound and tends to kink ; when it kinks it usually snaps. When available, tantellum wire may replace stainless steel ; it is strong, but is softer than stainless steel and easier to handle. Wire sutures show no tendency to migrate in the tissues, but loose ends left behind may travel far. Only once in our experience has the presence of a wire suture caused any damage to surrounding structures, and then because of omission of the essential step of cutting the ends back flush with the knot. One end of a suture in a lingula bronchus snapped two millimetres from the knot; this projecting end was not observed and later penetrated the pericardium, puncturing one of the coronary arteries, with a fatal result. Knots should be placed so that they do not lie in direct contact with pulsating blood vessels.

\section{Bronchial Closure}

Every wound involving division of a bronchus is potentially infected. We hold the view that delay in closure of the bronchial stump and subsequent fistula formation are due to infection in the stump and aggravation of that infection by the presence of foreign suture material inimical to the tissues. We have recently been called upon to drain a chronic post-lobectomy empyema pocket communicating with a broncho-pleural fistula; lying free in the pocket were two long pieces of heavy thread used to suture the bronchial stump at the time of the lobectomy. Other surgeons have reported cases of haemoptysis, and contralateral lung abscess formation, due to thread sutures ulcerating through the tissues of the stump. Whether closure occurs by healing of the bronchus or the peribronchial tissues is immaterial, as the healing process in either situation will be retarded by the presence of foreign bodies and chronic infection.

For the last two years wire has been used for the closure of lobar and main bronchi and the technique has gone through several stages of evolution (Fig. 1). First, wire was used in conjunction with thread-mattress sutures of thread above and one row of interrupted wire sutures over the end. Next, wire was used throughout for both mattress and end sutures. One day a bronchus had to be closed in a hurry and only the end row of wire sutures was inserted. The bronchus healed perfectly. In closing both main and lobar bronchi we now use a single row of interrupted 36-gauge stainless steel wire sutures over the end of the bronchus, including at least one cartilaginous ring, and tied with reef-knots only tight enough to obtain apposition, with all knots pointing in the axis of the stump. Any 


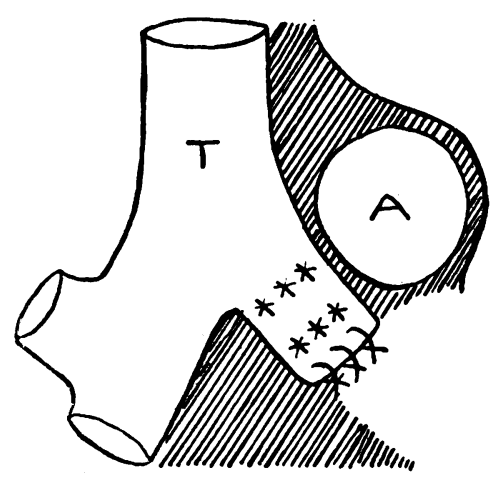

1

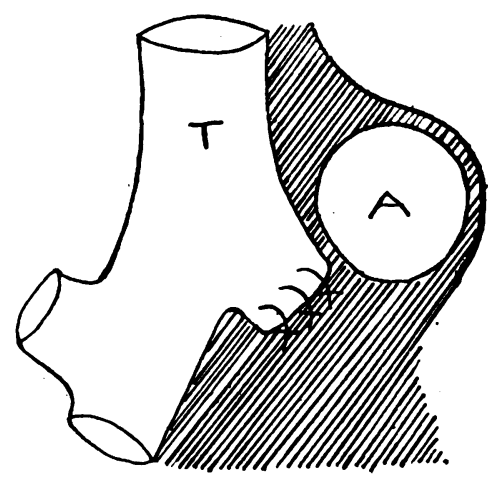

2

FIG. 1.-(1) Original method of closing left main bronchus with two rows of vertical mattress sutures and an end row of interrupted sutures. (2) New method, employing one end row of stainless steel wire sutures. Note the short stump which has retracted well into the mediastinum and is completely enveloped by mediastinal connective tissue.

attempt to dissect out the cartilaginous rings from the end of the bronchus has been found unnecessary. Sutures placed transversely at the angles have now been abandoned, as they are highly dangerous and tend to lie in contact with major mediastinal blood vessels (Fig. 2). The method is quick and the length of the operation has been shortened by 20 to $30 \mathrm{~min}$. It permits a high division of the bronchus and a short stump that retracts well into the mediastinum. On the

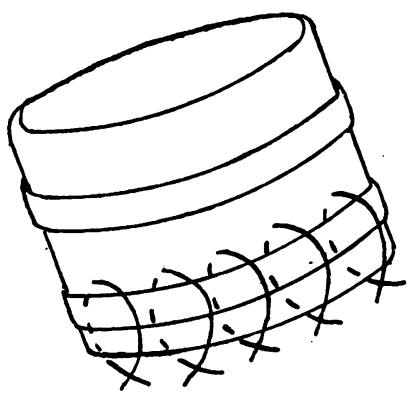

1

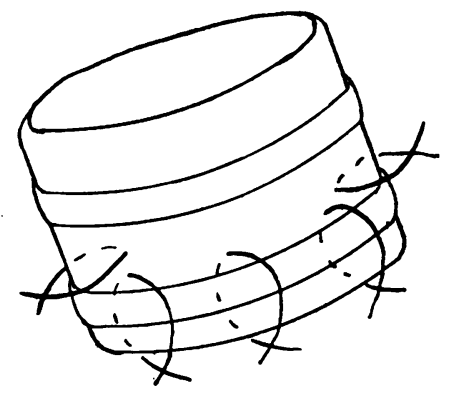

2

Fig. 2.-(1) Detail of closure of main bronchus, showing wire sutures encircling a bronchial cartilage; sutures placed in this way can do little harm. (2) Highly dangerous method now abandoned. The transverse sutures at the angles can perforate major mediastinal blood vessels. 
right side we resect part of the tracheal wall in order to obtain a vertical suture line which is readily covered by pleura, the azygos vein, and mediastinal connective tissue. This technique was evolved when late fistulae had been observed to occur in two cases at the outer angle of the bronchial stump when this had been sutured transversely as on the left side. There is less mediastinal tissue on the right side to heal over and around the suture line (Fig. 3).

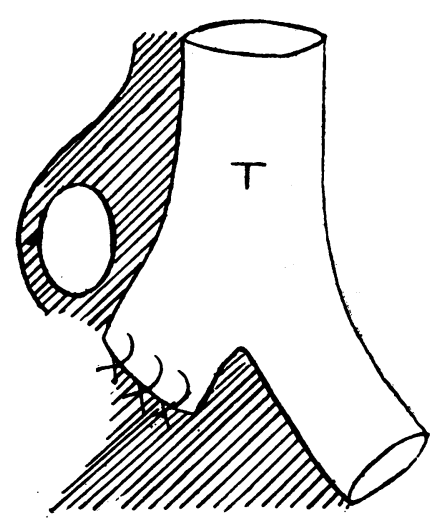

1

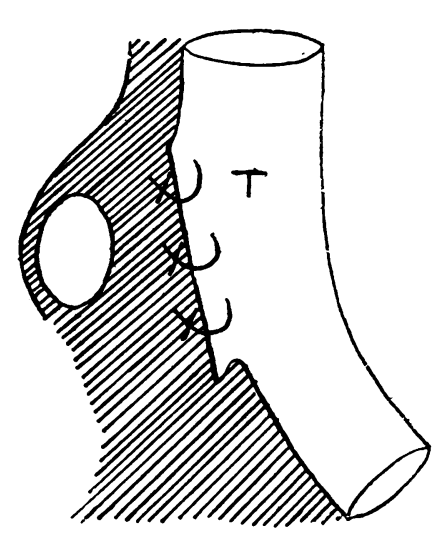

2

FIG. 3.-(1) Transverse closure of right main bronchus with wire technique. In two cases small fistulae occurred at the outer angle of the suture line. (2) Present technique showing vertical suture line well covered by azygos vein and mediastinal connective tissue. Five sutures are usually necessary. The azygos vein may have to be tied.

Penicillin and sulphanilamide powder have not been used, nor has any effort been made to cover the stump with pleura as we did not want to complicate the experiment by introducing additional variable factors. Most clinical experimental work is rendered valueless by complexity of the experiment, and we set out to investigate one thing only-namely, the effect of stainless steel sutures on bronchial closure; had these other factors been admitted, no conclusions could have been drawn from the results obtained. Tables I and II present the results of this method of bronchial closure following pneumonectomy and lobectomy for malignant and suppurative disease of the lungs. Only those cases that survived operation by at least four weeks or longer are included in these figures (Tables I and II). The two fistulae that occurred following pneumonectomy using wire technique were both on the right side, one appearing nine weeks after operation and the other four weeks ; since modifying the technique by shortening the stump still further, as in Fig. 3, no fistulae have occurred. 
TABLE I

Results Obtained by Various Methods of Bronchial Closure Following lobectomy

\begin{tabular}{|c|c|c|c|c|c|c|c|c|}
\hline \multicolumn{6}{|c|}{ Method of Closing Bronchus } & \multirow{2}{*}{$\begin{array}{c}\text { Cases } \\
38 \\
10 \\
14 \\
22\end{array}$} & \multirow{2}{*}{$\begin{array}{l}\text { Fistulae } \\
18 \\
3 \\
2 \text { (Temporary) } \\
0\end{array}$} & \multirow{2}{*}{$\begin{array}{r}\text { Empyemata } \\
14 \\
3 \\
4 \\
0\end{array}$} \\
\hline $\begin{array}{l}\text { Catgut } \\
\text { Thread } \\
\text { Thread } \\
\text { Wire }\end{array}$ & $\begin{array}{cr}. . & \ldots \\
\text { and } & \text { Wire } \\
\ldots & .\end{array}$ & $\begin{array}{l}\cdots \\
\cdots \\
\cdots\end{array}$ & $\begin{array}{l}\ldots \\
\cdots \\
\cdots \\
\ldots\end{array}$ & $\begin{array}{l}\ldots \\
\cdots \\
\ldots\end{array}$ & $\begin{array}{l}\cdots \\
\cdots \\
\cdots\end{array}$ & & & \\
\hline
\end{tabular}

It will be observed that condition "three," relating to statistical significance, has not yet been fully satisfied, as the number of cases is too small. Jones (1945) has used a similar technique for bronchial closure following pneumonectomy and lobectomy for pulmonary tuberculosis and finds it is the only method that has appreciably lowered the risk of fistula formation when operating for that condition.

One opportunity to compare the histological reaction of stump tissue to wire and thread sutures has been encountered. A man of 54 died, four weeks following a left pneumonectomy for carcinoma, from a fulminating putrid empyema occurring suddenly in the fourth week of convalescence. At autopsy the stump was soundly healed and there was no fistula. The thread sutures were ulcerating

TABLE II

Results Obtained by Various Methods of Closing the Main Bronchus Following PNEUMONeCTOMY

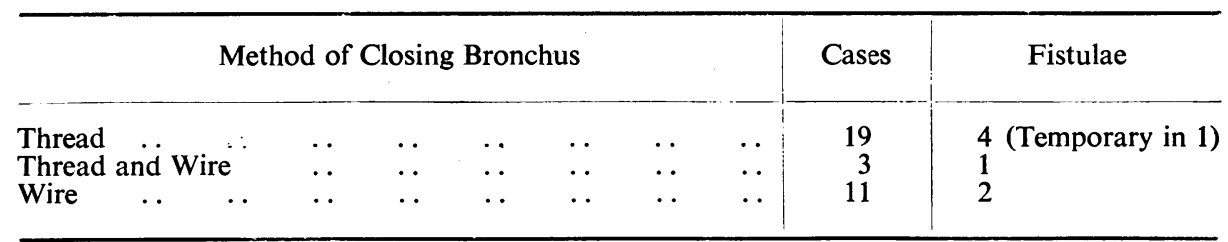

through into the lumen of the stump ; the wire sutures were firmly embedded in fibrous tissue, there was no corrosion of the wire, and neither macroscopic nor microscopic evidence of inflammatory tissue reaction was detectable.

\section{Secondary Suture of Infected Wounds of the Chest Wall}

As a result of the sound healing obtained in the presence of infection, the use of wire was extended. Open infected wounds of the chest wall in battle casualties were cleared of necrotic tissue, including bone, and sutured in layers, including the skin, with interrupted wire sutures. Skin sutures were removed in five days and primary union occurred in every case except one in which the whole of both cartilaginous costal margins had been resected on account of a foul suppurative chondritis. At first penicillin got the credit, but a control series treated without 
penicillin healed just as well. In no case did a sinus develop on account of the presence of buried wire sutures.

\section{REPAIR OF LUNG DEFECTS}

The reaction of lung parenchyma to the presence of stainless steel has been investigated. Not infrequently when decorticating chronic, clotted, or infected haemothoraces, large rents in the lung tissue containing fragments of bone or clothing were encountered. The rents were sutured with wire and no attempt was made to excise contused lung tissue or do wedge resections. We were impressed by the rapid return to normal of what appeared to be hopelessly damaged lung tissue, and the absence of infection. In dealing with retained foreign bodies in the lung our aim was to evolve the simplest technique consistent with sound healing and minimal damage to lung tissue. Our practice was to incise the lung down to the foreign body, remove it, and obliterate the cavity in which it lay by a few encircling sutures of wire; the incision into the lung was then closed with the same material. There has been no opportunity of examining histologically the reaction of human pulmonary tissues to the presence of stainless steel. Tomographic and bronchographic examination of the region of the sutures reveal minimal fibrosis and no bronchial dilatation unless present before operation.

\section{Closure of Persisting Broncho-cutaneous Fistulae}

The management of chronic broncho-cutaneous fistula, the result of drained but epithelized lung abscess, still remains a problem judging by the considerable variety of operations designed to cure the condition. The bar to healing and obliteration of the cavity and fistulous track is the cuboidal epithelial lining which spreads, from the orifices of the bronchi opening into the abscess cavity, until contact is established with the squamous epithelium of the skin at the mouth of the sinus. So far as the tissues are concerned, healing is complete when epithelization has occurred, and most of the muscle- and fat-grafting operations performed ignore the essential fact that no graft can "take" in an epithelized space. If the cavity is large and much lung tissue was destroyed by the original infection, then a segmental lobectomy is indicated. When only a fistulous track connects the bronchus to the chest wall sinus the simpler operation of excising the track completely and repairing the potentially infected wound in anatomical layers with interrupted sutures of stainless steel has given satisfactory results, and the wounds have shown no tendency to break down, with re-establishment of the fistula, as when other suture material has been used. One case of "lattice lung" with multiple bronchial fistulae had resisted the attacks of numerous surgeons for eight years, during which time a total thoracoplasty had been performed in stages. The layer of bronchial mucosa was excised completely, each fistula was ligated with wire, and the raw surface of lung was closed with interrupted wire sutures ; the chest wall was then repaired in layers with the same material, and healing occurred by first intention. 


\section{Closure of Thoracoplasty Wounds}

The question of post-thoracoplasty wound infection has caused no little concern, especially in cases of secondarily infected tuberculous empyemata in which the incidence is high. We encountered 14 instances of wound infection in 215 operations. Quite apart from gross wound infection with suppuration in the extrafascial space, which may delay completion of the thoracoplasty for weeks or months, the excessive tissue reaction to catgut, with pools of serum or sterile pus round every stitch and generalized oedema of the tissues, has resulted in the average interval between stages being prolonged to three weeks. The use of thread for the muscle layers has been accompanied by less tissue reaction, but when infection does occur it is almost invariably followed by chronic sinus formation and delay in healing until some of the sutures have sloughed out. In a recent series of cases sutured throughout with interrupted stainless steel sutures in the muscle layers and continuous wire in the skin, the rapid healing and absence of oedema have been impressive and the tissues have been ready for the next stage in seven to ten days. No infection has occurred despite obvious wound contamination from draining empyema sinuses in two cases, but in one case part of the wound had to be resutured when the skin stitches were removed owing to some carelessly tied muscle sutures coming undone. In reopening the wound for the second stage scissors must be used, as the scalpel is rapidly blunted by the wire ; no attempt is made to remove the wire unless it comes to hand easily. Another advantage of wire in thoracoplasty closure is that it rapidly discourages the habit of inserting one's fingers into the wound. But the technique is time-consuming and tedious and is reserved for cases which are in good shape at the end of operation or where infection is anticipated.

Histological examination of muscle tissue 14 days after its insertion shows the usual layer of acellular collagen next to the wire but no inflammatory reaction and no destruction of muscle fibres.

\section{Plastic Reconstruction of Major Air Passages}

An opportunity to test the use of stainless steel in the plastic repair of the major air passages was recently encountered. A woman of 42 was admitted to the unit with a recurrent adenoma of the intrathoracic segment of the trachea. Obstruction had been present for three years, during which time several courses of radiotherapy, diathermy cauterization, and an attempt at excision through the right pleural cavity had failed. So severe was her stridor and distress that a desperate attempt to relieve the obstruction was called for. The adenomatous nature of the tumour was confirmed by a further biopsy. Through a right transpleural approach practically the whole of the intrathoracic part of the trachea, from thoracic inlet to carina, containing an extensive sessile adenomatous tumour, was excised. Only a narrow strip of tracheal wall $\frac{1}{4}$ in. wide from the left-hand 
wall was retained. A spiral of 32 -gauge stainless steel wire, 3 in. long, was ther sutured between the cut ends of the trachea, over the cuff of the anaesthetist's tube, and surrounded by a large free graft of fascia from the thigh ; the graft was sutured into position with 39-gauge wire sutures. The right upper lobe was then sutured to the mediastinum, the lung was inflated, and the chest closed. Convalescence was uneventful except for a dry irritating cough for the first two weeks. At no time was there any evidence of infection in the reconstructed trachea. The patient now has a perfect airway and is free from symptoms. This case will be reported in greater detail at a later date (Fig 4).

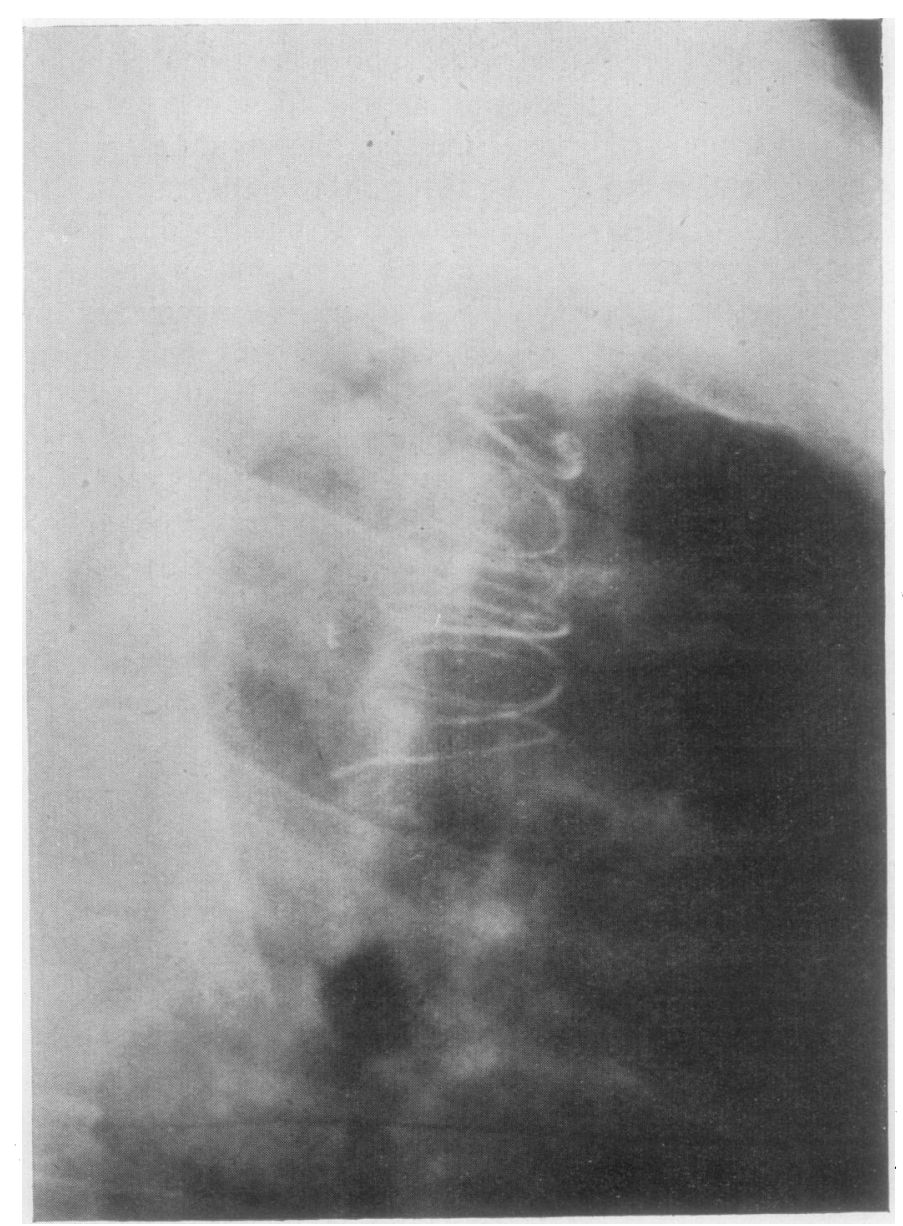

FIG. 4.-Lateral radiograph of region of reconstructed trachea, showing stainless steel wire "skeleton," three months after its insertion. 


\section{CONCLUSION}

A preliminary report upon the application of stainless steel wire suture technique to thoracic surgery is presented. The use of wire in the chest will depend to a certain extent upon the temperament of the surgeon. Stainless steel has proved to be completely inert to the tissues, but extremely irritant to the surgeon, and the technique requires patience and self-control. In our hands the advantages have outweighed the disadvantages, and we believe that any simple technique that can lower the incidence of wound infection and bronchial fistula from 50 per cent to virtually nil is worth a little extra trouble.

\section{REFERENCES}

Babcock, W. W. (1935). Amer. J. Surg., 27, 67.

Bell, R. H. (1942). Milit. Surg., Wash., 91, 185.

Bunnell, S. (1940). Amer. J. Surg.. 47, 502.

Dulin, J. W. (1943). J. Iowa med. Soc., 33, 546.

Genkins, M. H. (1938). Penn. med. J., 41, 707.

Gordon, S. D. (1943). Canad. med. Ass. J., 48, 406.

Grad, H. (1935). Amer. J. Obstet. Gynec., 30, 863.

Harris, R. I. (1944). Lancet, 1, 504.

Holman, C. W., and Eckel, J. H. (1941). Surg. Gynec. Obstet., 72, 1052.

Jones, J. C. (1945). J. Thorac. Surg., 14, 1.

Jones, T. E., Newell, E. T. Jr., and Brubaker, R. E. (1941). Surg. Gynec. Obstet., 72, 1056.

Kaufman, L. R., Johnson, W. W., and Lesser, A. (1939). Ibid., 69, 684.

Large, O. P. (1943). Amer. J. Surg., 60, 415.

Localio, S. A.. Casale, W., and Hinton. J. W. (1943). Surg. Gynec. Obstet., 77, 243.

(1943). Ibid, 77, 376.

(1943). Ibid., 77, 481 .

Nichols, H. M. (1943). West. J. Surg., 51, 17.

Pfeiffer, G. E. (1941). Northw. Med. Seattie, 40, 8.

Pratt, G. H. (1942). Surg. Gynec. Obstet., 74, 845.

Preston, D. J. (1940). Amer. J. Surg., 49, 56.

(1941). Surgery, 9, 896.

Smiley, K. E. (1940). Trans. Amer. proctol. Soc., 41, 191.

Vickers, H. D. (1944). Nav. Med. Bull., Wash., 42, 140.

Wu, Y. K., and Pai, H. C. (1942). Surg. Gynec. Obstet., 74, 110.

- (1943). Chin. med. J., 61, 132. 